\title{
Molecular pathology of neurodegenerative diseases: principles and practice
}

\author{
Gabor G Kovacs
}

Laboratory Medicine Program, University Health Network, Toronto, Ontario, Canada

\section{Correspondence to}

Gabor G Kovacs, Laboratory Medicine Program, University Health Network, Toronto, ON M5G 2C4, Canada; Gabor. kovacs@uhnresearch.ca

Received 12 July 2019 Revised 25 July 2019 Accepted 26 July 2019 Published Online First 8 August 2019
A Check for updates

(c) Author(s) (or their employer(s)) 2019. No commercial re-use. See rights and permissions. Published by BMJ.

To cite: Kovacs GG. J Clin Pathol

2019:72:725-735.

\section{ABSTRACT}

Neurodegenerative diseases are characterised by selective dysfunction and progressive loss of synapses and neurons associated with pathologically altered proteins that deposit primarily in the human brain and spinal cord. Recent discoveries have identified a spectrum of distinct immunohistochemically and biochemically detectable proteins, which serve as a basis for proteinbased disease classification. Diagnostic criteria have been updated and disease staging procedures have been proposed. These are based on novel concepts which recognise that (1) most of these proteins follow a sequential distribution pattern in the brain suggesting a seeding mechanism and cell-to-cell propagation; (2) some of the neurodegeneration-associated proteins can be detected in peripheral organs; and (3) concomitant presence of neurodegeneration-associated proteins is more the rule than the exception. These concepts, together with the fact that the clinical symptoms do not unequivocally reflect the molecular pathological background, place the neuropathological examination at the centre of requirements for an accurate diagnosis. The need for quality control in biomarker development, clinical and neuroimaging studies, and evaluation of therapy trials, as well as an increasing demand for the general public to better understand human brain disorders, underlines the importance for a renaissance of postmortem neuropathological studies at this time. This review summarises recent advances in neuropathological diagnosis and reports novel aspects of relevance for general pathological practice.

\section{DEFINITION AND CLASSIFICATION OF NEURODEGENERATIVE DISEASES}

Neurodegenerative diseases (NDDs) are characterised by progressive dysfunction of synapses, neurons, glial cells and their networks. A crucial component of NDDs is the deposition of physicochemically altered variants of physiological proteins in the nervous system. Importantly, not only neurons but glial cells also accumulate these pathological proteins. ${ }^{1}$

The classification of NDDs is based on the clinical presentation, anatomical regions and cell types affected, conformationally altered proteins involved in the pathogenetic process, and aetiology if known (ie, genetic variations or acquired pathways, for example, in prion diseases). ${ }^{23}$ Importantly, (1) the clinical symptoms are determined by the anatomical region showing neuronal dysfunction and not necessarily by the distribution of the altered protein; and (2) NDD-associated proteins show a wide spectrum of biochemical modifications and can accumulate in neurons or glial cells (intracellular), or deposit in extracellular locations such as plaques, including those showing amyloid characteristics. Accordingly, the best approach to NDDs is to define anatomical, cellular and protein vulnerability patterns. ${ }^{14}$

Clinical manifestations begin either as (1) cognitive decline, dementia and alterations in high-order brain functions (ie, involvement of the hippocampus, entorhinal cortex, limbic system and neocortical areas); (2) movement disorders, including hyperkinetic, hypokinetic, cerebellar, or upper and lower motor neuron dysfunction (ie, involvement of the basal ganglia, thalamus, brainstem nuclei, cerebellar cortex and nuclei, motor cortical areas, and lower motor neurons of the spinal cord); or (3) early combinations of these. ${ }^{2}$ A subset of dementia is called frontotemporal dementia, which is associated with the degeneration of the frontal and temporal lobes (frontotemporal lobar degeneration, FTLD). Affected areas show atrophy or altered metabolic activity in neuroimaging, and atrophy at postmortem macroscopical and neuronal loss and reactive astrogliosis at microscopical inspection.

The molecular pathological classification focuses on the distinction of synaptic, intracellular and extracellular protein accumulations. ${ }^{1}$ The subcellular location of the intracellular deposits (eg, nuclear, cytoplasmic or cell process) is also important. Many new antibodies have been developed for immunohistochemistry which describe novel immunostaining patterns. For the diagnostic classification, however, not all protein immunoreactive morphologies are considered. Although for subtyping of diseases morphological criteria are used predominantly, biochemistry and genetic analysis are often required as a complementary examination to immunohistochemistry. It should be mentioned that there are some forms of NDDs, exemplified by hereditary spastic paraplegia or some variants of spinocerebellar ataxia, where no specific protein inclusions are detected with currently available methods.

The following proteins are associated with the majority of sporadic and genetic adult-onset $\mathrm{NDDs}^{5}$ : (1) amyloid-beta $(\mathrm{A} \beta)$, which is cleaved from the transmembrane amyloid precursor protein (APP), a 770-aa protein-the APP gene has been mapped to chromosome 21q21.3; (2) $\alpha$-synuclein, a 140 -aa protein encoded by a gene (SNCA) on chromosome 4 ; (3) prion protein $(\mathrm{PrP})$, which is a 253-aa protein encoded by the gene of PrP (PRNP) located on chromosome 20 ; (4) the microtubule-associated protein tau is represented by different isoforms and encoded by a single gene (MAPT) on chromosome 17q21; (5) transactive response DNA-binding protein 43 (TDP-43), a highly 

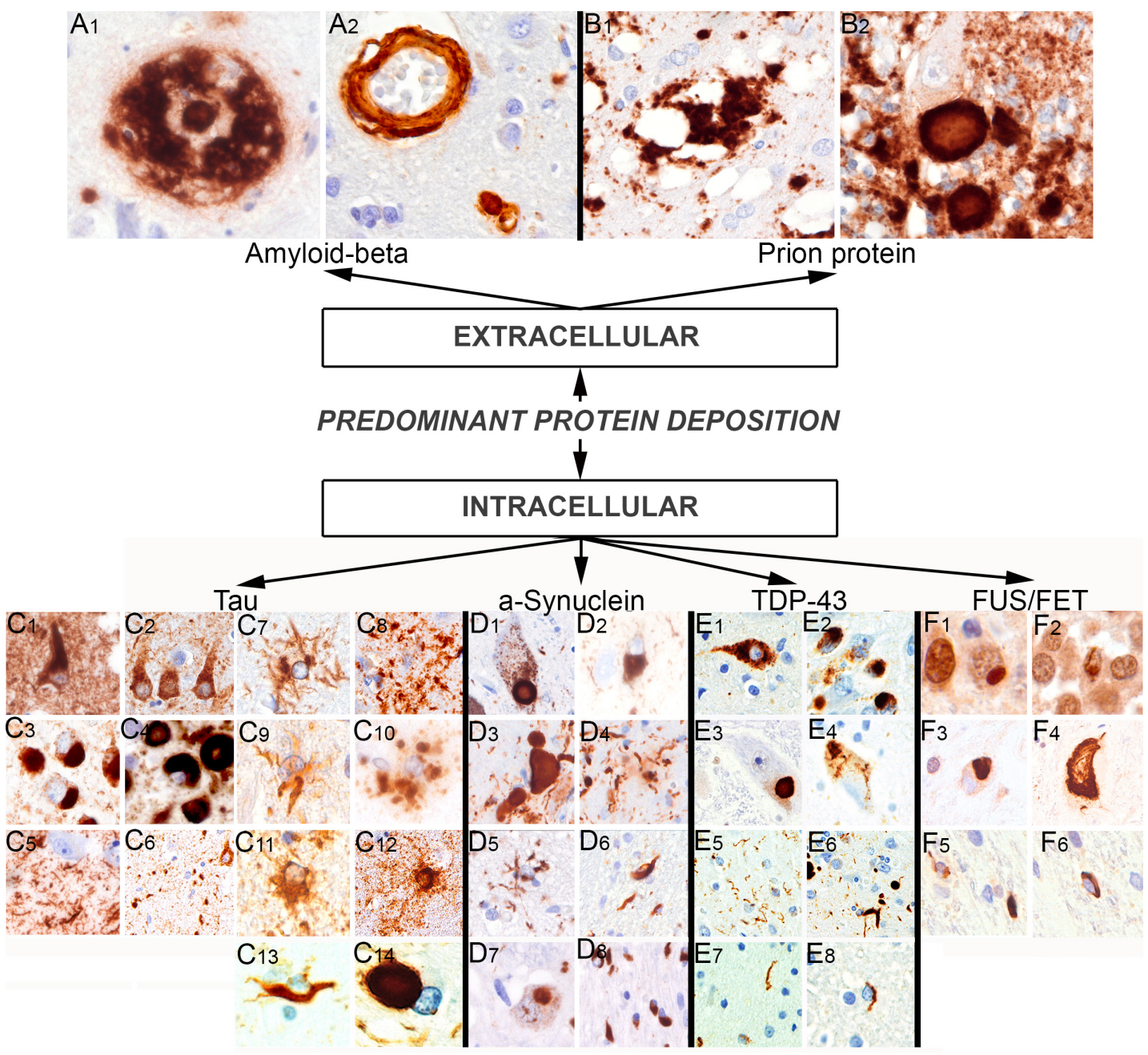

Figure 1 Protein immunoreactivities in neurodegenerative diseases. Amyloid-beta immunoreactive cored plaque (A1) and cerebral amyloid angiopathy (A2). Patchy/perivacuolar (B1) and kuru-plaque (B2) type immunoreactivity for the prion protein. Tau-positive neurofibrillary tangle (C1), pretangle (C2), 3-repeat tau isoform positive Pick body (C3), 4-repeat tau isoform positive spherical inclusion (C4), tau-positive neuropil threads in axons (C5) and grains in dendrites (C6). Tau-positive tufted astrocyte (C7), astrocytic plaque (C8), ramified astrocyte (C9), globular astroglial inclusion (C10), thorn-shaped astrocyte (C11), granular/fuzzy astrocyte (C12), oligodendroglial coiled body (C13) and globular oligodendroglial inclusion (C14). $\alpha$-Synuclein-positive brainstem-type Lewy body (D1), cortical-type Lewy body (D2), Lewy neurite (D3), thin neurites (D4), astrocyte (D5), oligodendrocyte (D6) in Parkinson's disease and neuronal cytoplasmic and nuclear inclusions (D7), and oligodendroglial cytoplasmic PappLantos body (D8) in multiple system atrophy. TDP-43 immunoreactive granular (E1), compact (E2 and E3) and skein-like (E4) deposits in neurons; thin (E5) and thick (E6) neurites in the grey matter; and thin threads (E7) and oligodendroglial inclusion (E8) in the white matter. FUS immunoreactive compact cytoplasmic (F1; right side of image, compared with the physiological nuclear immunostaining of the neuron on the left side of the image) and vermiform nuclear (F2) neuronal inclusion in the granular cells of the dentate gyrus; compact (F3) and tangle-like (F4) inclusions in lower motor neurons; and white matter threads (F5) and oligodendroglial inclusion (F6). FUS, fused in sarcoma; TDP-43, transactive response DNA-binding protein 43 .

conserved nuclear 414-aa protein encoded by the TARDBP gene on chromosome 1; and (6) FET (abbreviation of the following three proteins) proteins, which include the fused in sarcoma (FUS), Ewing's sarcoma RNA-binding protein 1 (EWSR1) and TATA-binding protein-associated factor 15 (TAF15). ${ }^{6}$ There are further proteins associated with hereditary disorders such as neurological trinucleotide repeat disorders, neuroserpin, ferritin-related NDDs and familial cerebral amyloidosis. ${ }^{1}$

Accordingly, we distinguish tauopathies, $\alpha$-synucleinopathies, TDP-43 proteinopathies, FUS/FET proteinopathies, prion diseases, trinucleotide repeat diseases, neuroserpinopathy, ferritinopathy and cerebral amyloidosis. $\mathrm{A} \beta$, as one of the most frequently detected NDD-associated proteins, accumulates in Alzheimer's disease (AD) together with tau. Immunoreactive morphologies of different proteinopathies and their distribution are shown in figures 1 and 2 .

\section{ASPECTS OF DISEASE PATHOGENESIS WITH IMPLICATIONS FOR THE DIAGNOSTIC PROCEDURE}

Traditionally accepted pathogenic aspects of NDDs comprise molecular damage, dysregulation of energetic and ion homeostasis, and metabolic changes. ${ }^{7}$ The proteinopathy concept emphasises the role of protein processing systems and highlights important aspects of pathogenesis, such as the unfolded protein response, ${ }^{8}$ and protein elimination pathways, such as the ubiquitin-proteasome system and the autophagy-lysosome pathway. ${ }^{9}$ A novel concept, referred to as prion-like spreading, suggests 


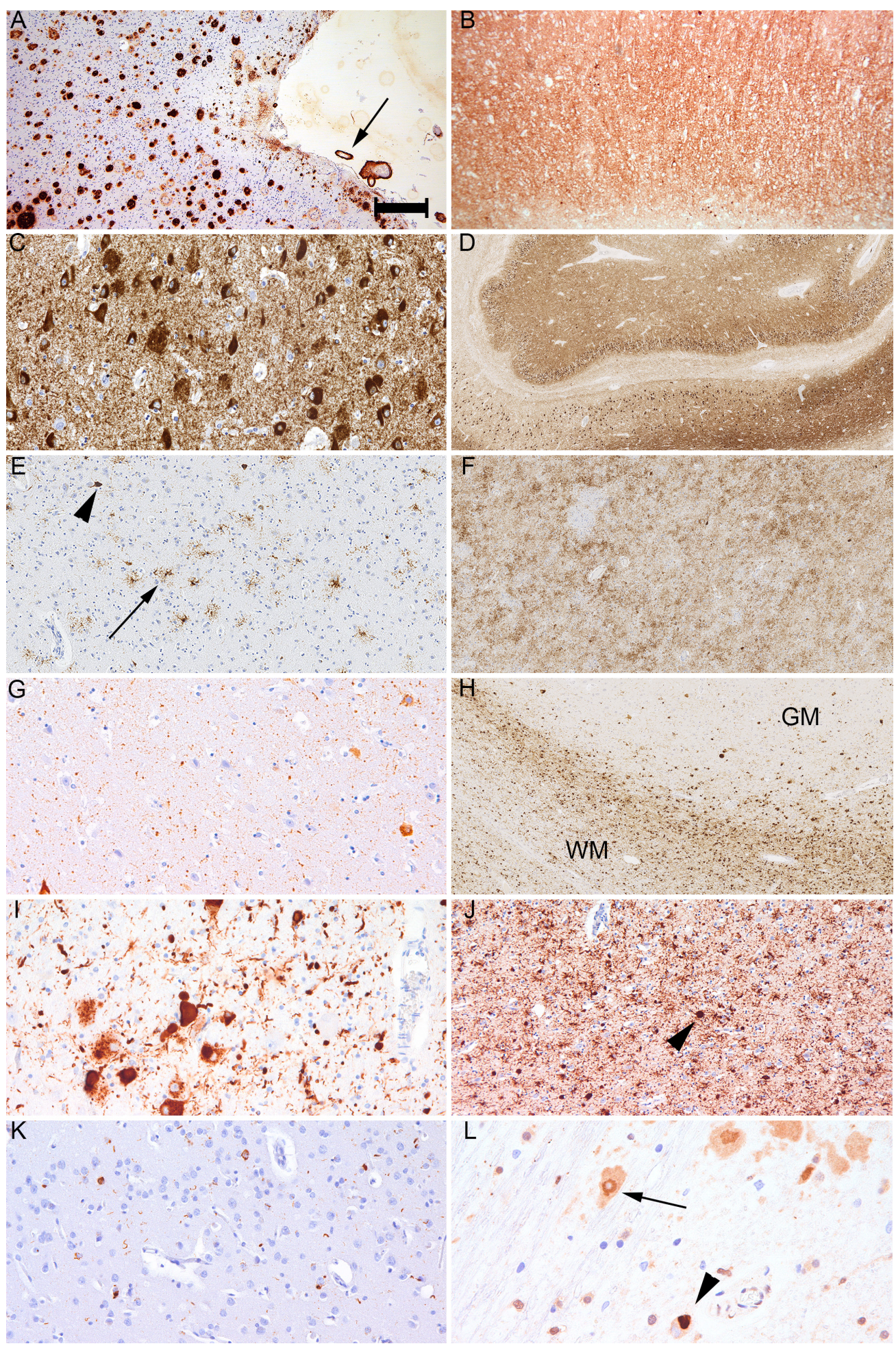

Figure 2 Distribution of protein immunoreactivity in various neurodegenerative conditions. Amyloid-beta immunoreactivity in the frontal cortex in Alzheimer's disease (A). The arrow indicates cerebral amyloid angiopathy. Diffuse/synaptic immunoreactivity for disease-associated prion protein in the frontal cortex in Creutzfeldt-Jakob disease (B). Tau-positive neurofibrillary tangles in Alzheimer's disease (C) and Pick bodies (D) in the hippocampus; tufted astrocytes (arrow) and neuronal tau immunoreactivity (arrowhead) in progressive supranuclear palsy (E) and astrocytic plaques and threads in corticobasal degeneration (F) in the frontal cortex; pretangles and grains in argyrophilic grain disease (G) and globular oligodendroglial inclusions in the white matter (WM) contrasting the grey matter (GM) in globular glial tauopathy (H) in the hippocampus. $\alpha$-Synuclein-positive intraneuronal Lewy bodies and Lewy neurites in Parkinson's disease in the substantia nigra (I) and cortical Lewy bodies (one indicated by an arrowhead) together with neurites and immunoreactive astrocytes in dementia with Lewy bodies (J). Phosphorylated TDP-43 immunoreactive neuronal cytoplasmic and neuritic immunoreactive in frontotemporal lobar degeneration with TDP-43 pathology in the frontal cortex (K). FUS-positive neuronal cytoplasmic inclusion (arrowhead) contrasting the physiological nuclear staining (arrow) in the spinal cord in familial amyotrophic lateral sclerosis with FUS mutation. The bar in A represents $400 \mu \mathrm{m}$ for A, B, D and F; $200 \mu \mathrm{m}$ for E, G, H and J; $100 \mu \mathrm{m}$ for I and $\mathrm{K}$; and $40 \mu \mathrm{m}$ for L. FUS, fused in sarcoma; TDP-43, transactive response DNA-binding protein 43. 
that the proteins associated with NDDs propagate in the nervous system and involve anatomical areas in a sequential/hierarchical fashion. This concept stems from prion disease research and proposes template-directed protein misfolding and cell-to-cell propagation of pathological NDD-associated proteins. ${ }^{10}$ Exposure of susceptible hosts to cognate molecular templates has been proposed for cerebral neurodegenerative conditions and for systemic amyloidosis, also described as 'inducible proteopathies'. ${ }^{11}$ Indeed, for most of the above-mentioned proteins, evidence from cell culture and animal experimental models has revealed that cells can take up pathological proteins and propagate pathology to surrounding cells. ${ }^{12}$ Cell-to-cell prion-like propagation should not, however, be confused with humanto-human transmissibility as seen in prion diseases. Therefore, the public health relevance is different for prion diseases and non-prion NDDs, such as AD and/or Parkinson's disease (PD). The conceptual levels of protein propagation include basically four levels, reflected by the experimental approach used to demonstrate the spreading, such as molecular, tissue, systemic and infectious propagons. ${ }^{13}$ Infectious propagons have been defined as 'proteins that transmit pathological conformation between individuals'. ${ }^{13}$ However, under very unusual situations, seeds of $A \beta$ have been shown to propagate from human grafted dura mater containing pathological $\mathrm{A} \beta .^{14}$ Importantly, only in prion diseases the whole clinicopathological phenotype ('phenotype propagon'), ${ }^{14}$ together with the pathological conformer of the PrP, can be effectively and rapidly transmitted from human to human. Although the current trend is to interpret the progressive neuronal damage as a consequence of cell-to-cell propagation, the classical selective vulnerability hypothesis suggests that protein aggregation is initiated in a subset of neurons that are vulnerable to certain harmful conditions. ${ }^{15}$

The property of self-propagation was exploited to establish real-time quaking-induced conversion assays (RT-QuIC) for the detection of disease-associated PrP in human CreutzfeldtJakob disease (CJD). ${ }^{16}$ Based on the concept of amyloid seeding, proteins capable of misfolding will seed the assembly of the recombinant protein into amyloid fibrils that generate fluorescence of thioflavin-T. ${ }^{17}$ Recent studies have shown that this method also works in biofluid samples, such as cerebrospinal fluid, for the detection of PrP, and for $\alpha$-synuclein and different isoforms of tau protein. ${ }^{17}$

The recognition of sequential involvement of anatomical regions, supported by the recent cell-to-cell propagation theory, led to the development of stages and phases of pathological

Table 1 Stages and phases reported for various tau pathologies and amyloid-beta deposition

\begin{tabular}{|c|c|c|c|}
\hline \multirow[t]{5}{*}{ Amyloid-beta $(A D)^{38}$} & \multicolumn{2}{|l|}{ Frontal, parietal, temporal or occipital neocortex. } & Phase 1 \\
\hline & \multicolumn{2}{|l|}{ Entorhinal region, CA1 and in the insular cortex. } & Phase 2 \\
\hline & \multicolumn{2}{|c|}{ Basal ganglia, basal forebrain nuclei, thalamus, hypothalamus, white matter. } & Phase 3 \\
\hline & \multicolumn{2}{|c|}{$\begin{array}{l}\text { Inferior olivary nucleus, the reticular formation of the medulla oblongata, substantia nigra, CA4, } \\
\text { central grey of the midbrain, colliculi superiores and inferiores, red nucleus. }\end{array}$} & Phase 4 \\
\hline & \multicolumn{2}{|c|}{ Different nuclei of the pons, cerebellum. } & Phase 5 \\
\hline \multirow[t]{7}{*}{ Tau $(A D)^{4546162}$} & \multicolumn{2}{|l|}{ Locus coeruleus, magnocellular nuclei of the basal forebrain. } & Stage $a-c$ \\
\hline & \multicolumn{2}{|l|}{ Transentorhinal region. } & Stage I \\
\hline & \multicolumn{2}{|l|}{ Entorhinal cortex. } & Stage II \\
\hline & \multicolumn{2}{|l|}{ Fusiform and lingual gyri, amygdala, anterior thalamus. } & Stage III \\
\hline & \multicolumn{2}{|l|}{ Superior temporal gyrus. } & Stage IV \\
\hline & \multicolumn{2}{|c|}{ Frontal, superolateral and occipital (peristriate) regions, striatum. } & Stage V \\
\hline & \multicolumn{2}{|c|}{ Secondary and primary neocortical regions and striate area in the occipital lobe, substantia nigra. } & Stage VI \\
\hline \multirow[t]{4}{*}{ Tau (AGD) 107150} & \multicolumn{2}{|c|}{ Ambient gyrus. } & Stage 1 \\
\hline & \multicolumn{2}{|c|}{ Anterior and posterior medial temporal lobe, temporal pole, subiculum, entorhinal cortex. } & Stage 2 \\
\hline & \multicolumn{2}{|c|}{ Septum, insular cortex and anterior cingulate gyrus. } & Stage 3 \\
\hline & \multicolumn{2}{|l|}{ Neocortex and brainstem. } & Stage 4 \\
\hline \multirow[t]{4}{*}{ Tau (Pick) ${ }^{149}$} & \multicolumn{2}{|l|}{ Frontotemporal limbic/paralimbic and neocortical regions. } & Phase 1 \\
\hline & \multicolumn{2}{|l|}{ Basal ganglia, locus coeruleus and raphe nuclei. } & Phase 2 \\
\hline & \multicolumn{2}{|l|}{ Primary motor cortex and precerebellar nuclei. } & Phase 3 \\
\hline & \multicolumn{2}{|l|}{ Visual cortex. } & Phase 4 \\
\hline \multirow[t]{4}{*}{ Tau (astro-PSP) ${ }^{30}$} & \multicolumn{2}{|l|}{ Striatum. } & Stage 1 \\
\hline & \multicolumn{2}{|l|}{ Frontal-parietal to temporal, to occipital. } & Stage 2 \\
\hline & \multicolumn{2}{|l|}{ Amygdala. } & Stage 3 \\
\hline & \multicolumn{2}{|l|}{ Brainstem. } & Stage 4 \\
\hline \multirow[t]{4}{*}{ Tau (astro-CBD) $)^{30}$} & \multicolumn{2}{|l|}{ Frontal-parietal. } & Stage 1 \\
\hline & Temporal to occipital. & & Stage 2 \\
\hline & Striatum and/or amygdala. & & Stage 3 \\
\hline & Brainstem. & & Stage 4 \\
\hline Tau (GM ARTAG) ${ }^{30}$ & Striatum. & Amygdala. & Stage 1 \\
\hline & Cortex or amygdala or brainstem. & Striatum or cortex or brainstem. & Stage 2 \\
\hline & $\begin{array}{l}\text { Striatum + amygdala + cortex or striatum + amygdala } \\
+ \text { brainstem. }\end{array}$ & $\begin{array}{l}\text { Striatum }+ \text { amygdala }+ \text { cortex or striatum }+ \text { amygdala }+ \\
\text { brainstem or amygdala }+ \text { cortex }+ \text { brainstem. }\end{array}$ & Stage 3 \\
\hline & All regions. & All regions. & Stage 4 \\
\hline
\end{tabular}

AD, Alzheimer's disease; AGD, argyrophilic grain disease; CA, cornu ammonis; CBD, corticobasal degeneration; GM ARTAG, grey matter ageing-related tau astrogliopathy; PSP, progressive supranuclear palsy. 
Table 2 Stages, phases and patterns reported for various $\alpha$-synuclein and TDP-43 pathologies

\begin{tabular}{|c|c|c|}
\hline \multirow[t]{4}{*}{ TDP-43 (bvFTD) $)^{151}$} & Orbital gyri, gyrus rectus and amygdala. & Pattern I \\
\hline & $\begin{array}{l}\text { Middle frontal and anterior cingulate gyrus, anteromedial temporal lobe areas, superior and medial temporal gyri, } \\
\text { striatum, red nucleus, thalamus, precerebellar nuclei. }\end{array}$ & Pattern II \\
\hline & Motor cortex, bulbar somatomotor neurons and the spinal cord anterior horn. & Pattern III \\
\hline & Visual cortex. & Pattern IV \\
\hline \multirow[t]{4}{*}{ TDP-43 (ALS) ${ }^{152}$} & Agranular motor cortex, brainstem motor nuclei of cranial nerves V, VII and X-XII, and spinal cord a-motoneurons. & Stage 1 \\
\hline & Prefrontal neocortex (middle frontal gyrus), brainstem reticular formation, precerebellar nuclei and the red nucleus. & Stage 2 \\
\hline & Prefrontal (gyrus rectus and orbital gyri), and then postcentral neocortex and striatum. & Stage 3 \\
\hline & Anteromedial portions of the temporal lobe, including the hippocampus. & Stage 4 \\
\hline \multirow[t]{6}{*}{ TDP-43 (AD) $)^{154}$} & Amygdala. & Stage 1 \\
\hline & Entorhinal cortex and subiculum. & Stage 2 \\
\hline & Dentate gyrus of the hippocampus and occipitotemporal cortex. & Stage 3 \\
\hline & Insular cortex, ventral striatum, basal forebrain and inferior temporal cortex. & Stage 4 \\
\hline & Substantia nigra, inferior olive and midbrain tectum. & Stage 5 \\
\hline & Basal ganglia and middle frontal cortex. & Stage 6 \\
\hline \multirow[t]{4}{*}{ aSyn (MSA-P) $)^{156}$} & $\begin{array}{l}\text { Striatum, lentiform nucleus, substantia nigra, brainstem white matter tracts, cerebellar subcortical white matter, motor } \\
\text { cortex, mid-frontal cortex and sensory cortex. }\end{array}$ & Phase 1 \\
\hline & Spinal cord and thalamus. & Phase 2 \\
\hline & Hippocampus and amygdala. & Phase 3 \\
\hline & Visual cortex. & Phase 4 \\
\hline \multirow[t]{4}{*}{ aSyn (MSA-C) ${ }^{155}$} & Cerebellum and cerebellar brainstem connectivities. & Phase 1 \\
\hline & Pyramidal and extrapyramidal white matter. & Phase 2 \\
\hline & Neocortex and basal ganglia grey matter. & Phase 3 \\
\hline & Amygdala and hippocampus. & Phase 4 \\
\hline \multirow[t]{6}{*}{ aSyn $(\text { Lewy) })^{72}$} & Dorsal IX/X motor nucleus and/or intermediate reticular zone (medulla oblongata). & Stage 1 \\
\hline & Caudal raphe nuclei, gigantocellular reticular nucleus, coeruleus-subcoeruleus complex (pons). & Stage 2 \\
\hline & Pars compacta of the substantia nigra (midbrain). & Stage 3 \\
\hline & Temporal mesocortex (transentorhinal region, amygdala) and allocortex (CA2-plexus). & Stage 4 \\
\hline & High-order sensory association areas of the neocortex and prefrontal neocortex. & Stage 5 \\
\hline & $\begin{array}{l}\text { First-order sensory association areas of the neocortex and premotor areas, mild changes in primary sensory areas and } \\
\text { the primary motor field. }\end{array}$ & Stage 6 \\
\hline
\end{tabular}

AD, Alzheimer's disease; ALS, amyotrophic lateral sclerosis; C, cerebellar type; CA, Cornu Ammonis; MSA, multiple system atrophy; P, parkinsonian type; TDP-43, Transactive response (TAR) DNAbinding protein 43; aSyn, $\alpha$-synuclein; bvFTD, behavioural variant of frontotemporal dementia.

protein deposits (see below and in tables 1 and 2). Accordingly, examination of a single anatomical area (eg, neurosurgical biopsy) can be only suggestive of the presence of a certain disease. The propagation of proteins along nerves has implications for general pathologists also. Indeed, deposits of NDD-associated proteins can be detected in peripheral organs associated with neural structures. ${ }^{18} 19$ This has been studied and demonstrated most extensively for $\alpha$-synuclein. ${ }^{20}$ Several studies suggest that $\alpha$-synuclein has the ability to spread from the gastrointestinal tract to the brain and vice versa, which has led to the hypothesis that disorders of the gastrointestinal tract (ie, inflammation or dysbiosis of the gut microbiota) may trigger $\alpha$-synuclein aggregation as an early step in the pathogenesis of $\alpha$-synucleinopathies. ${ }^{21}$ Interestingly, a recent study described disease-associated PrP deposits in the vagus nerve in sporadic and genetic CJD, arguing for diverse transport mechanisms and direction of transport. ${ }^{22}$ The concept of proteinopathies, and particularly the idea on propagation, has led to the development of novel therapeutic strategies. The aim of these is either to interact with the processing or biochemical modification of a specific protein (eg, $\mathrm{A} \beta$ metabolism or tau modifications), ${ }^{23-27}$ or to target pathological protein forms with therapeutic antibodies (eg, $A \beta, \alpha$-synuclein and tau). ${ }^{23-28}$ It must be noted, however, that for example for $A \beta$ the therapeutic trials were not clearly effective, ${ }^{25-27}$ either due to the incorrectly defined target, too late initiation of the therapy (ie, patients already showing clinical symptoms), or due to comorbidities and multimorbidities (see below).

The pathological process of intracellular protein aggregation also undergoes a process of maturation. Preaggregates, detectable only by specific antibodies, will later become fibrillar and ubiquitinated, and can then be visualised by antiubiquitin, anti-p62 immunohistochemistry and various silver stainings. ${ }^{29-31}$ Thus, the protein-based classification and the frequent co-occurence of deposits composed of various proteins require the application of a wide spectrum of immunostainings for a diagnosis. Additional stainings useful for the characterisation of pathologies include silver stainings (Bielschowsky, Bodian, Campbell-Switzer and Gallyas $^{32}$ and thioflavin staining. Although silver techniques have greatly contributed to the understanding of NDDs, their use has been hampered by the complexity of the techniques and lack of standardised protocols, leading to interlaboratory variability. ${ }^{33}$ More recently, in diagnostic practice, ubiquitin and p62/sequestome-1 immunohistochemistry have replaced silver staining for the detection of various abnormal protein deposits. ${ }^{34}$

Finally, for diagnostic practice it is crucial to understand the concept of concomitant pathologies. This concept describes the frequent observation that, in addition to the hallmark lesions of a specific NDD, further pathological alterations can be observed in the same brain. ${ }^{356}$ While the threshold of clinical impairment may be reached by a sufficient amount of a single proteinopathy, 
it could alternatively be reached by the combined and additive presence of various disorders that in isolation are not sufficient to cause clinical symptoms. ${ }^{24}$ The concurrent presence of brain (ie, neurodegenerative disorder) and systemic (ie, metabolic or vascular) disorders with different pathogenic aspects has been defined as multimorbidity to distinguish from those with overlapping pathogenic aspects termed as comorbidity, such as combinations of neurodegenerative proteinopathies. ${ }^{37}$ Importantly, proteinopathy comorbidities are seen associated with several gene mutations. ${ }^{37}$ In the ageing brain particularly, a large variety of comorbidities and multimorbidities can be detected, ${ }^{4}$ which hampers the translation of neuropathological disease subtyping into clinically easily interpretable biomarkers and emphasises the critical role of postmortem examination, which should include the examination of peripheral organs as well.

\section{OVERVIEW OF DIAGNOSTIC MOLECULAR NEUROPATHOLOGY OF NDDS \\ Alzheimer's disease}

$\mathrm{AD}$ is characterised by the extracellular deposition of $\mathrm{A} \beta$ fibrils and by the intraneuronal accumulation of abnormally phosphorylated tau protein. $\mathrm{A} \beta$ and tau pathology in $\mathrm{AD}$ often follows a stereotypical pattern. This is described as phases for $A \beta$ deposition, ${ }^{38}$ based on the progressive involvement of isocortical areas (phase 1), hippocampus and entorhinal cortex, ${ }^{2}$ basal ganglia and diencephalon, ${ }^{3}$ brainstem, ${ }^{4}$ and cerebellum. ${ }^{5} \mathrm{~A} \beta$ cerebral amyloid angiopathy (CAA) frequently but not necessarily associates with the parenchymal deposits and is distinguished as capillary (type 1) or non-capillary type (type 2), also showing three stages. ${ }^{39} 40$ The Consortium to Establish a Registry for Alzheimer's Disease (CERAD) $)^{41}$ criteria were based on the detection of argyrophilic neuritic plaques, which represent only a subset of $\mathrm{A} \beta$ immunomorphologies. Detecting $\mathrm{A} \beta$ deposits in the brain without tau pathology is not sufficient for the diagnosis of $\mathrm{AD}$. However, this is now discussed as preclinical AD in vivo based on the presence of biomarkers, ${ }^{42}{ }^{43}$ or postmortem by the presence of AD-type neuropathological alterations despite no signs of cognitive decline during life. Regarding tau pathology, the sequence of tau deposition starts in the transentorhinal cortex (stage I), followed by the entorhinal cortex (II), inferior (III) and middle temporal gyri (IV), followed by neocortical areas such as the occipital cortex (peristriate for stage $\mathrm{V}$ and striate cortex for stage VI). ${ }^{4-46}$ Recent studies have shown that subcortical nuclei also show early tau pathology, ${ }^{47} 48$ which are now discussed also as early subcortical stages a, b and c, ${ }^{49} 50$ or as early precortical phase. ${ }^{51}$ This also fits with the concept of preclinical AD; thus, protein deposition starts decades before the first clinical symptoms. Furthermore, based on the assessment of the distribution of neurofibrillary tangles (NFTs), clinicopathological subtypes of $\mathrm{AD}$, for example, hippocampal sparing, typical or limbic-predominant, have been proposed, ${ }^{52}$ arguing for further subclassification of AD. In summary, for the current neuropathological diagnosis of $\mathrm{AD}$, based on the recommendation of the National Institute on Aging-Alzheimer's Association, an 'ABC' score for the description of $\mathrm{AD}$ neuropathological change incorporates the phases of $A \beta$ deposition (score $A$ for 'amyloid'), stages of tau-positive neurofibrillary degeneration (score B, for 'Braak') and appearance of argyrophilic neuritic plaques (score $C$ for 'CERAD'), which have to be documented and interpreted together by transforming the $\mathrm{ABC}$ scores into one of four levels of $\mathrm{AD}$ neuropathological change: not, low, intermediate or high. $^{53}$

\section{Prion diseases}

Prion diseases are classified based on the aetiology as idiopathic/sporadic, acquired and genetic forms. A clinicopathological grouping is based on historical descriptions, which define phenotypes as Creutzfeldt-Jakob disease (CJD: spongiform encephalopathy; sporadic, iatrogenic, variant or genetic), kuru, Gerstmann-Sträussler-Scheinker disease (PrP-amyloidosis), and familial or sporadic fatal insomnia (selective thalamic degeneration without prominent spongiform change).$^{54}$ Immunohistochemistry or western blotting for disease-associated $\operatorname{PrP}$ is important for the definitive diagnosis of prion diseases. Based on immunostaining for disease-associated PrP, biochemical examination of the size of the protease-resistant core of the abnormal $\operatorname{PrP}$ (ie, type 1 migrating at $21 \mathrm{kDa}$ and type 2 at $19 \mathrm{kDa}$ ), combined with the genotype at the polymorphic codon 129 (methionine, $\mathrm{M}$, or valine, $\mathrm{V}$ ) of the $\operatorname{PrP}$ gene (PRNP), at least six major molecular subtypes and their combinations are recognised for sporadic CJD. ${ }^{55-58}$ The combination of these molecular features distinguishes the bovine spongiform encephalopathy-related acquired form variant CJD, iatrogenic CJD, the recently described disorder termed variably protease-sensitive prionopathy (VPSPr), and certain genetic forms of disease. In VPSPr, typical protease-resistant $\operatorname{PrP}$ was undetectable with standard diagnostic procedures, and abnormal PrP was detected only after enrichment at concentrations much lower than common prion diseases showing a distinct ladderlike electrophoretic profile. ${ }^{59}$

Immunohistochemistry for disease-associated $\operatorname{PrP}$ reveals a wide range of morphologies; however, it is critical to recognise florid plaque-like structures, which are a characteristic sign of variant CJD, although it has been described in iatrogenic CJD as well. ${ }^{60}$ Peripheral organs also accumulate disease-associated $\mathrm{PrP}$ in humans depending on the aetiological subtype. ${ }^{61-67}$ Most importantly, the lymphoreticular tissue shows PrP immunoreactivity in variant CJD. ${ }^{68}$ In certain genetic prion diseases, CAA has been described, ${ }^{69}$ while vessel wall deposition without amyloid characteristics has been described in variant and sporadic CJD. ${ }^{70}$ In summary, differentiation of acquired or genetic forms requires data on the aetiology (ie, to exclude acquired forms) and sequencing of the PRNP, together with morphology and immunoblotting of the disease-associated PrP.

\section{$\boldsymbol{\alpha}$-Synucleinopathies}

For the classification of $\alpha$-synucleinopathies, currently only clinical and morphological aspects are considered. Two major groups are distinguished: the neuron-predominant $\alpha$-synucleinopathies showing Lewy body pathology, and multiple system atrophy (MSA) which is dominated by glial cytoplasmic inclusions (PappLantos bodies). Diseases with Lewy bodies are further stratified based on the clinical data (movement disorder or cognitive decline as early symptom) as dementia with Lewy bodies (DLB), PD, and PD with dementia. Lewy bodies may be detected incidentally without prominent clinical symptoms (ie, incidental Lewy body disease). One neuropathological approach to Lewy body disorders is the staging of $\alpha$-synuclein pathology according to Braak and colleagues, ${ }^{71}$ which includes the sequential involvement of the medulla oblongata (stage 1), pons (2) mesencephalon (3; eg, the substantia nigra), limbic areas (4) and neocortical areas (5 and 6). ${ }^{72}$ However, this approach has been criticised since some cases do not strictly follow these stages, suggesting that there are disease forms with Lewy bodies where $\alpha$-synuclein pathology is generated 'spontaneously' in a specific region. ${ }^{71}$ Another procedure is applied in the diagnostic criteria for DLB (ie, brainstem, limbic and neocortical types), ${ }^{73}$ which originates 
from the classification by Kosaka et al. ${ }^{74}$ Since the olfactory bulb is a region affected early, and there are disease forms where Lewy bodies are restricted to the amygdala, ${ }^{7576}$ there are further suggestions for classification. The unified staging system for Lewy body disorders classifies Lewy body disorders as olfactory bulb only, brainstem-predominant, limbic-predominant, brainstem and limbic, and neocortical. ${ }^{77}$

The mere presence of oligodendroglial inclusions (PappLantos bodies) is sufficient for the diagnosis of MSA. ${ }^{78}$ Clinical subtypes such as MSA-P (parkinsonism dominant) and MSA-C (cerebellar symptom-predominant) are defined for MSA where the distribution of glial inclusions might follow striatonigral or olivopontocerebellar predominance. ${ }^{79}$ These differences cannot be clearly translated into biochemical or morphological differences. Recently, a further type has been described with FTLD..$^{80} 81$

Further underappreciated $\alpha$-synuclein immunoreactivities in Lewy body diseases comprise those in astrocytes and oligodendrocytes. ${ }^{82}{ }^{83} \alpha$-Synuclein immunoreactive deposits can be observed in the ependyma, perivascular cells, cranial nerves, retina, gastrointestinal tract, peripheral organs and skin. ${ }^{84-97}$ $\alpha$-Synuclein immunoreactivity in MSA has been described in subpial and periventricular astrocytes ${ }^{98}$ and in Schwann cells. ${ }^{99}$ Furthermore, $\alpha$-synuclein immunoreactivity in skin biopsy tissues in MSA shows differences from that in patients with PD. ${ }^{9497}$

\section{Tauopathies}

Tauopathies are classified as primary (when tau pathology is the driving force in the pathogenesis) or secondary. Primary tauopathies are grouped based on the ratio of 3 repeat (R)-tau and 4R-tau isoforms and two or three major bands $(60,64$ and $68 \mathrm{kDa}$ ) in western blot of sarkosyl-insoluble fractions, furthermore, based on the distinct involvement of anatomical areas and cell types, and ultrastructural features of tau filaments. ${ }^{100}$ Mutations in the microtubule-associated tau (MAPT) gene show a wide spectrum of tau pathologies but typically recapitulate features of sporadic tauopathies. ${ }^{101} 102$

The 3R tauopathy Pick's disease is characterised by neuronal spherical Pick bodies, ramified astrocytes and less frequently, small oligodendroglial globular inclusions. ${ }^{103} 104$ 4R tauopathies comprise progressive supranuclear palsy (PSP), corticobasal degeneration (CBD), globular glial tauopathies (GGT) and argyrophilic grain disease (AGD). PSP is characterised by NFTs predominating the brainstem-subcortical areas associated with variable amounts of tufted astrocytes and coiled bodies. CBD is characterised by spherical neuronal inclusions (which are 4R-tau immunoreactive contrasting the $3 \mathrm{R}$ immunoreactive Pick bodies) and diffuse cytoplasmic tau immunoreactivity of neurons. These are seen together with astrocytic plaques, threads and coiled bodies of oligodendrocytes predominating cortical and subcortical (eg, basal ganglia) and less the brainstem areas. ${ }^{105}$ The distinguishing features of GGTs are the abundant astroglial and/or oligodendroglial inclusions with globular morphology. ${ }^{106}$ Comparably less neuronal inclusions comprising 4R immunoreactive spherical inclusions, globular NFT-like structures and diffuse cytoplasmic tau immunoreactivity are seen. AGD is characterised by neuronal dendritic grains and diffuse cytoplasmic tau immunoreactivity with additional granular/fuzzy astrocytes and oligodendroglial coiled bodies in a limbic distribution. ${ }^{107}$ The mixed 3R and $4 \mathrm{R}$ tauopathy affecting the medial temporal lobe, termed also as NFT-predominant dementia, represents the severe end of primary age-related tauopathy (PART). ${ }^{108}$ The concept of PART has been developed to recognise an almost universally detectable pathology at autopsy among elderly individuals clinically either lacking symptoms or showing amnestic cognitive changes. PART can be interpreted as part of early AD pathology but can represent also an independent process eventually progressing to NFT-predominant dementia. ${ }^{108} \mathrm{~A}$ further frequent finding in the ageing brain is ageing-related tau astrogliopathy (ARTAG), which describes tau-positive astrocytes in subpial, subependymal and perivascular locations, and white and grey matter. ${ }^{109}$ Finally, due to its high societal impact, chronic traumatic encephalopathy (CTE) has to be mentioned; this neuropathological term includes tau pathology of neuronal and astroglial tau morphologies following mild repetitive head injury that shows a peculiar distribution (eg, depth of cortical sulci). ${ }^{110}$ Although astroglial tau pathology shows overlap with ARTAG, strict criteria emphasise that the diagnosis of CTE requires the combined presence of neuronal and astroglial pathologies. ${ }^{110}$

\section{TDP-43 proteinopathies}

TDP-43 is a major component of the ubiquitin-positive inclusions that characterise amyotrophic lateral sclerosis (ALS) and a common form of FTLD. Importantly, a high number of cases (up to $40 \%$ ) show genetic alterations, such as mutations in the C9orf72 (most frequent), granulin (GRN), valosin-containing protein (VCP), TARDBP (the gene encoding TDP-43), SQSTM1 (sequestome), DCTN1 (dynactin), TBK1 (TANK-binding kinase) and OPTN (optineurin) genes. ${ }^{111-121}$ Importantly, C9orf72 expansion repeat mutation cases contain additional p62-positive, TDP-43-negative neuronal cytoplasmic inclusions composed of dipeptide repeat proteins, which are translated from the C9orf72 expansion repeats. ${ }^{114}$

TDP-43 immunoreactive structures are observed as neuronal cytoplasmic inclusions, dystrophic neurites, neuronal intranuclear inclusions and glial cytoplasmic inclusions; furthermore, skein-like and spherical inclusions are described in ALS. ${ }^{122-127}$ A harmonised classification system distinguishes four subtypes (A-D) based on the predominance and layer, predominance of neuritic and neuronal cytoplasmic, or intranuclear inclusions. ${ }^{128}$ These patterns can also predict the genes involved in hereditary forms. Finally a further type (E) has been described in rapidly progressive forms (duration $<3$ years) ${ }^{129}$; this awaits further confirmation from larger cohorts.

TDP-43 pathology frequently associates with other disorders, including $\mathrm{AD}$, $\mathrm{DLB}$, hippocampal sclerosis of ageing (a disorder affecting about $10 \%$ of individuals over the age of 85 years) $)^{130}$ and CTE. ${ }^{131}$ Some of these associations are related to genetic or other risk factors. ${ }^{5} 130132-135$ The cellular distribution of TDP-43 pathology may resemble that observed in FTLD-TDP, with only rare neuronal nuclear inclusions and variable presence of glial deposits. To recognise a stereotypical medial temporal lobe-predominant TDP-43 proteinopathy in older adults, with or without coexisting hippocampal sclerosis pathology that is associated with an amnestic dementia syndrome mimicking AD-type dementia, recently an entity termed limbic-predominant age-related TDP-43 encephalopathy (LATE) has been defined. ${ }^{136}$ LATE is supposed to describe the clinical disorder, while the neuropathological changes are termed LATE-NC. ${ }^{136}$

\section{FET/FUS proteinopathies}

Rare sporadic disorders associated with FTLD, such as basophilic inclusion body disease, atypical FTLD-U and neuronal intermediate filament inclusion disease, show neuronal (cytoplasmic/ nuclear) and glial cytoplasmic inclusions immunoreactive for FET proteins. ${ }^{6}{ }^{137-139}$ The inclusion types and their regional distribution in FTLD distinguish these forms in the majority of 
cases. In contrast, FUS gene mutation-related ALS cases are only immunoreactive for FUS and not for further FET proteins. ${ }^{6}$

\section{Rare disease forms}

Rare disease forms include mostly genetic NDDs with abnormal protein inclusions. One group of disorders is associated with the expansion of unstable trinucleotide repeats, such as inherited ataxias and Huntington's disease. Further rare inherited disorders associated with proteins and genes include neuroserpin. ${ }^{140-144}$ In ferritin-related NDDs, the molecular genetic defect resides in the ferritin light polypeptide gene and leads to the accumulation of ferritin deposits in the nucleus and cytoplasm of neurons and glia, and also in endothelial cells, cells of the vascular adventitia, choroid plexus and leptomeningeal cells, and peripheral organs. ${ }^{145}$ Furthermore, there are hereditary cerebral amyloidoses where the deposited proteins include $A \beta$, transthyretin, gelsolin, cystatin, PrP and BRI2 protein. ${ }^{146}$ Some further disorders show inclusion bodies, which are immunoreactive only for the ubiquitin-proteasome system (ie, FTLD-UPS), or a variety of proteins as seen in intranuclear inclusion body disease. Finally, there are diseases where no specific inclusions have been described (eg, FTLD-ni; no inclusions), ${ }^{115}$ although histological signs of neurodegeneration can be observed. Further NDD conditions include those associated with brain iron accumulation, postencephalitic disorders, head trauma (eg, CTE) or others described in restricted geographical areas (eg, parkinsonism-dementia complex of Guam) that associate with various spectra of proteinopathy lesions.

\section{THE APPROACH TO COMORBIDITIES AND MULTIMORBIDITIES}

All of the above-mentioned disorders, even hereditary forms, show various degrees of comorbid proteinopathies. ${ }^{37}$ However, since pure forms of proteinopathies are still frequently observed, ${ }^{147}$ the notion of the current molecular classification is justified. This is of particular importance to elucidate which pathogenic pathways lead to neurodegeneration. Comorbid proteinopathies might show a different clinical course, which has implications for biomarker and therapeutic development, and therefore the neuropathological report has to include this information. The interpretation is complicated by the fact that abnormally deposited proteins exist in different phases or states of cell type, specific intracellular or extracellular aggregation or fibrillisation, and distinct protein depositions follow different phases or stages of sequential involvement of anatomical brain areas. ${ }^{10}$ The latter phenomenon has been described for NFTs, ${ }^{45}{ }^{46}$ PSP-related tau pathology, ${ }^{148}$ astrocytic tau pathologies, ${ }^{30}$ Pick's disease, ${ }^{149}$ AGD, ${ }^{107} 150$ TDP-43 protein-related FTLD and ALS, ${ }^{151} 152$ TDP-43 pathology accompanying AD or other disorders, ${ }^{153} 154 \alpha$-synuclein in PD $^{72}$ and in MSA, ${ }^{155} 156$ and $A \beta$ deposition (tables 1 and 2 ). ${ }^{38}$ Hence comorbid cases might show an end stage or phase of one proteinopathy and an early stage or phase of another NDD. In addition, genetic variations, age and gender effects ${ }^{157} 158$ and systemic and vascular disorders interpreted as multimorbidities influence the phenotype, dynamics and course of the disease. This implies that (1) a minimum number of strategic blocks should be used for the delineation of regional involvement of different proteinopathies; (2) finding lesions characteristic of an NDD should not prompt termination of mapping for other NDD-associated proteins; and (3) documentation of non-NDD multimorbidities should be included.

\section{PRACTICAL ASPECTS FOR GENERAL PATHOLOGISTS}

Neuropathological examination is performed in neuropathology diagnostic services for clinical reasons or in the frame of brain banking primarily for research purposes. General pathologists may also be asked to indicate a first opinion on a neuropathological condition and recognise when consultation of a specialised neuropathological service is essential. To enhance the quality of the neuropathological report, clinical and neuroradiological information is essential. In particular any suspicion of prion disease should be considered before start of the neuropathological work-up. This requires studying the clinical data for any rapidly progressive neuropsychiatric disorder ( $<2$ years' duration), the result of cerebrospinal fluid examination (eg, protein 14-3-3 or RT-QuIC examination), brain MRI (high signal intensities in the basal ganglia, thalamus and/or cortical areas) and electroencephalography report (eg, periodic sharp wave complex and/ or triphasic waves). In cases with a suspicion for prion disease, specific autopsy measures ${ }^{159}$ and country-specific regulations must be followed. The quality of the neuropathological report is greatly enhanced when the results of the general autopsy (cause of death; state of the cardiovascular system; inflammatory, infectious or neoplastic diseases; and so on) are considered. Sampling for the diagnostic procedure may be complemented by a series of additional blocks to be embedded in paraffin and stored. In particular, paraffin blocks are more suitable for future studies than resampling after prolonged formalin fixation. ${ }^{160}$ For brain banking purposes, blocks for freezing, preferably the immediate adjacent area for paraffin embedding, should be prepared. Finally, reports on peripheral organs and NDD-associated proteins should be followed closely, for example, when a gastrointestinal biopsy tissue will be requested to be evaluated, for example, for $\alpha$-synuclein immunoreactivity.

In summary, the state-of-the-art neuropathological examination should include several anatomical regions and immunostainings to be able to report stages or phases of proteinopathies and their combinations, and should be complemented by the examination of peripheral organs for NDD-associated proteins and for multimorbidities affecting the clinical course of the disease.

\section{FUTURE PERSPECTIVES}

The number of autopsies performed is in decline worldwide, which has a major impact on the fate of neuropathology. However, novel therapies and biomarkers continue to appear on the market, which need strict quality control and definite diagnoses, including consideration of the spectrum of comorbidities and multimorbidities. As a result of the general public becoming more informed, in part due to the internet, the interest of the general public is increasing for transparent studies on the human brain. Frequently, by providing feedback on the disease, neuropathologists are able to impart a positive psychological effect on family members, helping them come to terms with the situation that their relative has deceased due to a yet unfathomable devastating disorder. Scientific examinations on the human brain have enormous benefits compared with the required costs, and these aspects should be recognised by health services and by the stakeholders of scientific developments. To emphasise the expert role of the neuropathologist, Edward B Lee ${ }^{161}$ recommends the integration of all the diagnostic modalities available that assist in the classification of disease in the form of a layered diagnosis (eg, integrated diagnosis; histological, clinical, molecular classification; and additional layers such as biochemistry). ${ }^{161}$ Thus, we should return back to the previously successful times of communication between neuropathologists, clinicians, neuroradiologists 
and general pathologists to better serve the needs of society with excellent and transparent quality control, and last but not least to increase the value and appreciation of the neuropathological diagnostic service.

\section{Take home messages}

Loss of neurons and accumulation of proteins characterise neurodegenerative diseases.

- Most of these proteins follow a sequential distribution pattern in the brain.

- Seeding mechanism and cell-to-cell propagation of proteins is suggested.

- Some of the neurodegeneration-associated protein can be detected in peripheral organs.

- Concomitant presence of neurodegeneration-associated proteins is frequent.

\section{Handling editor Runjan Chetty.}

Acknowledgements The author would like to acknowledge the Edmond I Safra Program in Parkinson's Disease and the Rossy Program for PSP research.

Funding The author has not declared a specific grant for this research from any funding agency in the public, commercial or not-for-profit sectors.

Competing interests None declared.

Patient consent for publication Not required.

Provenance and peer review Not commissioned; externally peer reviewed.

ORCID iD

Gabor G Kovacs http://orcid.org/0000-0003-3841-5511

\section{REFERENCES}

1. Kovacs G. Molecular pathological classification of neurodegenerative diseases: turning towards precision medicine. Int J Mol Sci 2016;17:189

2. Kovacs GG. Current concepts of neurodegenerative diseases. EMJ Neurol 2014:1:78-86.

3. Kovacs GG. Introduction: classification of neurodegenerative diseases. In: Kovacs GG ed. Neuropathology of neurodegenerative diseases: a practical guide. Cambridge, U.K: Cambridge University Press, 2015: 1-8.

4. Kovacs GG, Milenkovic I, Wöhrer A, et al. Non-Alzheimer neurodegenerative pathologies and their combinations are more frequent than commonly believed in the elderly brain: a community-based autopsy series. Acta Neuropathol 2013;126:365-84.

5. Kovacs $\mathrm{GG}$, Botond $\mathrm{G}$, Budka H. Protein coding of neurodegenerative dementias: the neuropathological basis of biomarker diagnostics. Acta Neuropathol 2010;119:389-408

6. Neumann M, Bentmann E, Dormann D, et al. Fet proteins TAF15 and EWS are selective markers that distinguish FTLD with FUS pathology from amyotrophic lateral sclerosis with FUS mutations. Brain 2011;134:2595-609.

7. von Bernhardi R, Eugenín J. Alzheimer's disease: redox dysregulation as a common denominator for diverse pathogenic mechanisms. Antioxid Redox Signal 2012;16:974-1031.

8. Cornejo VH, Hetz C. The unfolded protein response in Alzheimer's disease. Semin Immunopathol 2013;35:277-92.

9. A.T. Nijholt D, De Kimpe L, L. Elfrink $H$, et al. Removing protein aggregates: the role of proteolysis in neurodegeneration. Curr Med Chem 2011;18:2459-76.

10. Brettschneider J, Tredici KD, Lee VM-Y, et al. Spreading of pathology in neurodegenerative diseases: a focus on human studies. Nat Rev Neurosci 2015;16:109-20.

11. Walker LC, LeVine $\mathrm{H}$, Mattson MP, et al. Inducible proteopathies. Trends Neurosci 2006;29:438-43

12. Guo JL, Lee VMY. Cell-To-Cell transmission of pathogenic proteins in neurodegenerative diseases. Nat Med 2014;20:130-8.

13. Eisele YS, Duyckaerts C. Propagation of A $B$ pathology: hypotheses, discoveries, and yet unresolved questions from experimental and human brain studies. Acta Neuropathol 2016;131:5-25.

14. Kovacs $\mathrm{GG}$, Lutz MI, Ricken $\mathrm{G}$, et al. Dura mater is a potential source of $A \beta$ seeds. Acta Neuropathol 2016;131:911-23.

15. Walsh DM, Selkoe DJ. A critical appraisal of the pathogenic protein spread hypothesis of neurodegeneration. Nat Rev Neurosci 2016;17:251-60.
16. Atarashi $R$, Wilham JM, Christensen $L$, et al. Simplified ultrasensitive prion detection by recombinant PrP conversion with shaking. Nat Methods 2008;5:211-2.

17. Saijo E, Groveman BR, Kraus A, et al. Ultrasensitive RT-QulC seed amplification assays for disease-associated tau, $\alpha$-synuclein, and prion aggregates. Methods Mol Biol 2019;1873:19-37.

18. Wakabayashi K, Mori F, Tanji K, et al. Involvement of the peripheral nervous system in synucleinopathies, tauopathies and other neurodegenerative proteinopathies of the brain. Acta Neuropathol 2010:120:1-12.

19. Dugger BN, Hoffman BR, Scroggins A, et al. Tau immunoreactivity in peripheral tissues of human aging and select tauopathies. Neurosci Lett 2019;696:132-9.

20. Orimo S, Ghebremedhin E, Gelpi E. Peripheral and central autonomic nervous system: does the sympathetic or parasympathetic nervous system bear the brunt of the pathology during the course of sporadic PD? Cell Tissue Res 2018;373:267-86.

21. Breen DP, Halliday GM, Lang AE. Gut-brain axis and the spread of $\alpha$-synuclein pathology: vagal highway or dead end? Mov Disord. 2019;34:307-16.

22. Kresl P, Rahimi J, Gelpi E, et al. Accumulation of prion protein in the vagus nerve in Creutzfeldt-Jakob disease. Ann Neurol 2019;85:782-7.

23. Jadhav S, Avila J, Schöll M, et al. A walk through tau therapeutic strategies. Acta Neuropathol Commun 2019;7.

24. Rösler TW, Tayaranian Marvian A, Brendel M, et al. Four-Repeat tauopathies. Prog Neurobiol 2019:101644:101644

25. Doggrell SA. Grasping at straws: the failure of solanezumab to modify mild Alzheimer's disease. Expert Opin Biol Ther 2018:18:1189-92.

26. Panza F, Solfrizzi V, Imbimbo BP, et al. Amyloid-directed monoclonal antibodies for the treatment of Alzheimer's disease: the point of no return? Expert Opin Biol Ther 2014;14:1465-76.

27. Valera E, Spencer B, Masliah E. Immunotherapeutic approaches targeting amyloid- $\beta, \alpha$-synuclein, and tau for the treatment of neurodegenerative disorders. Neurotherapeutics 2016;13:179-89.

28. Wang Z, Gao G, Duan C, et al. Progress of immunotherapy of anti- $\alpha$-synuclein in Parkinson's disease. Biomed Pharmacother 2019;115.

29. Bancher C, Brunner C, Lassmann H, et al. Tau and ubiquitin immunoreactivity at different stages of formation of Alzheimer neurofibrillary tangles. Prog Clin Biol Res 1989:317:837-48.

30. Kovacs $G G$, Xie $S X$, Robinson JL, et al. Sequential stages and distribution patterns of aging-related tau astrogliopathy (ARTAG) in the human brain. acta neuropathol commun 2018;6.

31. Kuusisto E, Parkkinen L, Alafuzoff I. Morphogenesis of Lewy bodies: dissimilar incorporation of $\alpha$-synuclein, ubiquitin, and p62. J Neuropathol Exp Neurol 2003:62:1241-53.

32. Uchihara T. Silver diagnosis in neuropathology: principles, practice and revised interpretation. Acta Neuropathol 2007:113:483-99.

33. Alafuzoff I, Pikkarainen M, Al-Sarraj S, et al. Interlaboratory comparison of assessments of Alzheimer disease-related lesions: a study of the BrainNet Europe Consortium. J Neuropathol Exp Neurol 2006:65:740-57.

34. Kuusisto E, Kauppinen T, Alafuzoff I. Use of p62/SQSTM1 antibodies for neuropathological diagnosis. Neuropathol Appl Neurobiol 2008;34:169-80.

35. Kovacs GG, Alafuzoff I, Al-Sarraj S, et al. Mixed brain pathologies in dementia: the BrainNet Europe Consortium experience. Dement Geriatr Cogn Disord 2008:26:343-50

36. Rahimi J, Kovacs GG. Prevalence of mixed pathologies in the aging brain. Alzheimers Res Ther 2014;6.

37. Kovacs GG. Are comorbidities compatible with a molecular pathological classification of neurodegenerative diseases? Curr Opin Neurol 2019;32:279-91.

38. Thal DR, Rüb U, Orantes $M$, et al. Phases of a beta-deposition in the human brain and its relevance for the development of AD. Neurology 2002:58:1791-800.

39. Thal DR, Ghebremedhin E, Rüb U, et al. Two types of sporadic cerebral amyloid angiopathy. J Neuropathol Exp Neurol 2002:61:282-93.

40. Thal DR, Griffin WST, de Vos RAl, et al. Cerebral amyloid angiopathy and its relationship to Alzheimer's disease. Acta Neuropathol 2008:115:599-609.

41. Mirra SS, Heyman A, McKeel D, et al. The Consortium to establish a Registry for Alzheimer's disease (CERAD): Part II. standardization of the neuropathologic assessment of Alzheimer's disease. Neurology 1991:41:479-86.

42. Jack CR, Holtzman DM. Biomarker Modeling of Alzheimer's Disease. Neuron 2013:80:1347-58.

43. Jack CR, Wiste HJ, Weigand SD, et al. Age-Specific population frequencies of cerebral $\beta$-amyloidosis and neurodegeneration among people with normal cognitive function aged 50-89 years: a cross-sectional study. The Lancet Neurology 2014:13:997-1005

44. Alafuzoff I, Arzberger T, Al-Sarraj S, et al. Staging of neurofibrillary pathology in Alzheimer's disease: a study of the BrainNet Europe Consortium. Brain Pathol 2008:18:484-96.

45. Braak $\mathrm{H}$, Alafuzoff I, Arzberger T, et al. Staging of Alzheimer disease-associated neurofibrillary pathology using paraffin sections and immunocytochemistry. Acta Neuropathol 2006;112:389-404

46. Braak H, Braak E. Neuropathological stageing of Alzheimer-related changes. Acta Neuropathol 1991;82:239-59. 
47. Attems J, Thomas A, Jellinger K. Correlations between cortical and subcortical tau pathology. Neuropathol Appl Neurobio/ 2012;38:582-90.

48. Grinberg LT, Rüb U, Ferretti REL, et al. The dorsal raphe nucleus shows phospho-tau neurofibrillary changes before the transentorhinal region in Alzheimer's disease. A precocious onset? Neuropathol Appl Neurobiol 2009;35:406-16.

49. Braak H, Del Tredici K. The pathological process underlying Alzheimer's disease in individuals under thirty. Acta Neuropathol 2011;121:171-81.

50. Braak H, Del Tredici K. The preclinical phase of the pathological process underlying sporadic Alzheimer's disease. Brain 2015;138:2814-33.

51. Stratmann $\mathrm{K}$, Heinsen $\mathrm{H}$, Korf $\mathrm{H}-\mathrm{W}$, et al. Precortical Phase of Alzheimer's Disease (AD)-Related Tau Cytoskeletal Pathology. Brain Pathol 2016;26:371-86.

52. Murray ME, Graff-Radford NR, Ross OA, et al. Neuropathologically defined subtypes of Alzheimer's disease with distinct clinical characteristics: a retrospective study. Lancet Neurol 2011;10:785-96.

53. Montine TJ, Phelps CH, Beach TG, et al. National Institute on Aging-Alzheimer's association guidelines for the neuropathologic assessment of Alzheimer's disease: a practical approach. Acta Neuropathol 2012;123:1-11.

54. Quadrio I, Perret-Liaudet A, Kovacs GG. Molecular diagnosis of human prion disease. Expert Opin Med Diagn 2011:5:291-306.

55. Parchi P, Castellani R, Capellari S, et al. Molecular basis of phenotypic variability in sporadc creudeldt-jakob disease. Ann Neurol 1996;39:767-78.

56. Parchi P, de Boni L, Saverioni D, et al. Consensus classification of human prion disease histotypes allows reliable identification of molecular subtypes: an interrater study among surveillance centres in Europe and USA. Acta Neuropathol 2012;124:517-29.

57. Parchi P, Giese A, Capellari S, et al. Classification of sporadic Creutzfeldt-Jakob disease based on molecular and phenotypic analysis of 300 subjects. Ann Neurol 1999:46:224-33.

58. Parchi P, Strammiello R, Notari S, et al. Incidence and spectrum of sporadic Creutzfeldt-Jakob disease variants with mixed phenotype and co-occurrence of PrPSc types: an updated classification. Acta Neuropathol 2009;118:659-71.

59. Gambetti P, Dong Z, Yuan J, et al. A novel human disease with abnormal prion protein sensitive to protease. Ann Neurol 2008;63:697-708.

60. Kretzschmar HA, Sethi S, Földvári Z, et al. latrogenic Creutzfeldt-Jakob disease with Florid plaques. Brain Pathol 2003;13:245-9.

61. Glatzel M, Abela E, Maissen M, et al. Extraneural pathologic prion protein in sporadic Creutzfeldt-Jakob disease. N Engl J Med 2003;349:1812-20.

62. Head MW, Northcott V, Rennison K, et al. Prion protein accumulation in eyes of patients with sporadic and variant Creutzfeldt-Jakob disease. Invest. Ophthalmol. Vis. Sci. 2003;44:342-6

63. Head MW, Ritchie D, Smith N, et al. Peripheral tissue involvement in sporadic, iatrogenic, and variant Creutzfeldt-Jakob disease: an immunohistochemical, quantitative, and biochemical study. Am J Pathol 2004:164:143-53.

64. Notari S, Moleres FJ, Hunter SB, et al. Multiorgan detection and characterization of protease-resistant prion protein in a case of variant CJD examined in the United States. PloS One 2010:5:e8765.

65. Peden AH, Ritchie DL, Head MW, et al. Detection and localization of PrPSC in the skeletal muscle of patients with variant, iatrogenic, and sporadic forms of Creutzfeldt-Jakob disease. Am J Pathol 2006;168:927-35.

66. Peden AH, Ritchie DL, Uddin HP, et al. Abnormal prion protein in the pituitary in sporadic and variant Creutzfeldt-Jakob disease. Journal of General Virology 2007:88:1068-72.

67. WHO. Who guidelines on tissue infectivity distribution in transmissible spongiform encephalopathies. Geneva: WHO Press, 2006.

68. Hilton DAet al. Specificity of lymphoreticular accumulation of prion protein for variant Creutzfeldt-Jakob disease. J Clin Pathol 2004;57:300-2.

69. Ghetti B, Tagliavini F, Takao M, et al. Hereditary prion protein amyloidoses. Clin Lab Med 2003;23:65-85. viii.

70. Koperek 0 , Kovács GG, Ritchie $\mathrm{D}$, et al. Disease-Associated prion protein in vessel walls. Am J Pathol 2002;161:1979-84.

71. Jellinger KA. A critical reappraisal of current staging of Lewy-related pathology in human brain. Acta Neuropathol 2008;116:1-16.

72. Braak H, Tredici KD, Rüb U, et al. Staging of brain pathology related to sporadic Parkinson's disease. Neurobiol Aging 2003;24:197-211.

73. McKeith IG, Dickson DW, Lowe J, et al. Diagnosis and management of dementia with Lewy bodies: third report of the DLB Consortium. Neurology 2005;65:1863-72.

74. Kosaka K, Tsuchiya K, Yoshimura M. Lewy body disease with and without dementia: a clinicopathological study of 35 cases. Clin Neuropathol 1988;7:299-305.

75. Popescu A, Lippa CF, Lee VM-Y, et al. Lewy bodies in the amygdala: increase of alpha-synuclein aggregates in neurodegenerative diseases with tau-based inclusions. Arch Neurol 2004;61:1915-9.

76. Uchikado H, Lin WL, DeLucia MW, et al. Alzheimer disease with amygdala Lewy bodies: a distinct form of alpha-synucleinopathy. J Neuropathol Exp Neurol 2006;65:685-97.

77. Beach TG, Adler CH, Lue L, et al. Unified staging system for Lewy body disorders: correlation with nigrostriatal degeneration, cognitive impairment and motor dysfunction. Acta Neuropathol 2009;117:613-34.
78. Trojanowski JQ, Revesz T. Neuropathology Working group on MSA. proposed neuropathological criteria for the post mortem diagnosis of multiple system atrophy. Neuropathol Appl Neurobiol 2007;33:615-20.

79. Jellinger KA. Neuropathology of multiple system atrophy: new thoughts about pathogenesis. Mov Disord. 2014;29:1720-41.

80. Aoki N, Boyer PJ, Lund C, et al. Atypical multiple system atrophy is a new subtype of frontotemporal lobar degeneration: frontotemporal lobar degeneration associated with $\alpha$-synuclein. Acta Neuropathol 2015;130:93-105.

81. Rohan Z, Rahimi J, Weis $\mathrm{S}$, et al. Screening for $\alpha$-synuclein immunoreactive neuronal inclusions in the hippocampus allows identification of atypical MSA (FTLD-synuclein). Acta Neuropathol 2015;130:299-301.

82. Kovacs $\mathrm{GG}$, Breydo L, Green R, et al. Intracellular processing of disease-associated alpha-synuclein in the human brain suggests prion-like cell-to-cell spread. Neurobiol Dis 2014;69C:76-92.

83. Rohan Z, Milenkovic I, Lutz MI, et al. Shared and distinct patterns of oligodendroglial response in $\alpha$-synucleinopathies and tauopathies. J Neuropathol Exp Neurol 2016:75:1100-9.

84. Adler $\mathrm{CH}$, Dugger BN, Hinni ML, et al. Submandibular gland needle biopsy for the diagnosis of Parkinson disease. Neurology 2014;82:858-64.

85. Beach TG, Adler CH, Dugger BN, et al. Submandibular gland biopsy for the diagnosis of Parkinson disease. J Neuropathol Exp Neurol 2013;72:130-6.10.1097/ NEN.0b013e3182805c72

86. Beach TG, Adler $\mathrm{CH}$, Sue LI, et al. Multi-Organ distribution of phosphorylated $\alpha$-synuclein histopathology in subjects with Lewy body disorders. Acta Neuropathol 2010;119:689-702.

87. Beach TG, Carew J, Serrano G, et al. Phosphorylated $\alpha$-synuclein-immunoreactive retinal neuronal elements in Parkinson's disease subjects. Neurosci Lett 2014:571:34-8

88. Del Tredici K, Hawkes $\mathrm{CH}$, Ghebremedhin E, et al. Lewy pathology in the submandibular gland of individuals with incidental Lewy body disease and sporadic Parkinson's disease. Acta Neuropathol 2010;119:703-13.10.1007/s00401-010 0665-2

89. Gelpi E, Navarro-Otano J, Tolosa E, et al. Multiple organ involvement by alphasynuclein pathology in Lewy body disorders. Mov Disord. 2014;29:1010-8

90. Mu L, Sobotka S, Chen J, et al. Alpha-Synuclein pathology and axonal degeneration of the peripheral motor nerves innervating pharyngeal muscles in Parkinson disease. J Neuropathol Exp Neurol 2013;72:119-29.

91. Rahimi J, Milenkovic I, Kovacs GG. Patterns of tau and $\alpha$-synuclein pathology in the visual system. J Parkinsons Dis 2015:5:333-40.

92. Kovacs $\mathrm{GG}$, Breydo L, Green R, et al. Intracellular processing of disease-associated $\alpha$-synuclein in the human brain suggests prion-like cell-to-cell spread. Neurobiol Dis 2014:69:76-92.

93. Seidel K, Mahlke J, Siswanto $S$, et al. The brainstem pathologies of Parkinson's disease and dementia with Lewy bodies. Brain Pathology 2015;25:121-35.

94. Doppler K, Weis J, Karl K, et al. Distinctive distribution of phospho-alpha-synuclein in dermal nerves in multiple system atrophy. Mov Disord. 2015;30:1688-92.

95. Ikemura M, Saito Y, Sengoku R, et al. Lewy body pathology involves cutaneous nerves. J Neuropathol Exp Neurol 2008;67:945-53.

96. Schneider SA, Boettner M, Alexoudi A, et al. Can we use peripheral tissue biopsies to diagnose Parkinson's disease? A review of the literature. Eur I Neurol 2015.

97. Zange L, Noack C, Hahn K, et al. Phosphorylated $\alpha$-synuclein in skin nerve fibres differentiates Parkinson's disease from multiple system atrophy. Brain 2015;138:2310-21.

98. Nakamura K, Mori F, Kon T, et al. Accumulation of phosphorylated $\alpha$-synuclein in subpial and periventricular astrocytes in multiple system atrophy of long duration. Neuropathology 2016;36:157-67.

99. Nakamura K, Mori F, Kon T, et al. Filamentous aggregations of phosphorylated $\alpha$-synuclein in Schwann cells (Schwann cell cytoplasmic inclusions) in multiple system atrophy. acta neuropathol commun 2015;3.

100. Kovacs GG. Tauopathies. Handb Clin Neurol 2017;145:355-68.

101. Forrest SL, Kril JJ, Stevens CH, et al. Retiring the term FTDP-17 as MAPT mutations are genetic forms of sporadic frontotemporal tauopathies. Brain 2018;141:521-34.

102. Ghetti B, Oblak AL, Boeve BF, et al. Invited review: frontotemporal dementia caused by microtubule-associated protein tau gene (MAPT) mutations: a chameleon for neuropathology and neuroimaging. Neuropathol Appl Neurobiol 2015;41:24-46.

103. Dickson DW. Pick's disease: a modern approach. Brain Pathol 1998:8:339-54.

104. Kovacs GG, Rozemuller AJM, van Swieten JC, et al. Neuropathology of the hippocampus in FTLD-Tau with Pick bodies: a study of the BrainNet Europe Consortium. Neuropathol Appl Neurobiol 2013;39:166-78.

105. Dickson DW. Neuropathologic differentiation of progressive supranuclear palsy and corticobasal degeneration. J Neurol 1999;246:II6-II15.

106. Ahmed Z, Bigio EH, Budka H, et al. Globular glial tauopathies (GGT): consensus recommendations. Acta Neuropathol 2013;126:537-44.

107. Ferrer I, Santpere G, van Leeuwen FW. Argyrophilic grain disease. Brain 2008:131:1416-32.

108. Crary JF, Trojanowski JQ, Schneider JA, et al. Primary age-related tauopathy (part): a common pathology associated with human aging. Acta Neuropathol 2014;128:755-66. 
109. Kovacs GG, Ferrer I, Grinberg LT, et al. Aging-Related tau astrogliopathy (ARTAG): harmonized evaluation strategy. Acta Neuropathol 2016;131:87-102.

110. McKee AC, Cairns NJ, Dickson DW, et al. The first NINDS/NIBIB consensus meeting to define neuropathological criteria for the diagnosis of chronic traumatic encephalopathy. Acta Neuropathol 2016;131:75-86.

111. Benussi A, Padovani A, Borroni B. Phenotypic heterogeneity of monogenic frontotemporal dementia. Front Aging Neurosci 2015;7:171.

112. Farrer MJ, Hulihan MM, Kachergus JM, et al. Dctn1 mutations in Perry syndrome. Nat Genet 2009;41:163-5.

113. Kovacs GG, van der Zee J, Hort J, et al. Clinicopathological description of two cases with SQSTM1 gene mutation associated with frontotemporal dementia. Neuropathology 2016:36:27-38.

114. Mackenzie IRA, Frick P, Neumann M. The neuropathology associated with repeat expansions in the C9orf72 gene. Acta Neuropathol 2014;127:347-57.

115. Mackenzie IRA, Neumann M, Bigio EH, et al. Nomenclature and nosology for neuropathologic subtypes of frontotemporal lobar degeneration: an update. Acta Neuropathol 2010;119:1-4.

116. van der Zee J, Gijselinck I, Dillen L, et al. A Pan-European Study of the C9orf72 Repeat Associated with FTLD: Geographic Prevalence, Genomic Instability, and Intermediate Repeats. Hum Mutat 2013:34:363-73.

117. van der Zee J, Van Langenhove T, Kovacs GG, et al. Rare mutations in SQSTM1 modify susceptibility to frontotemporal lobar degeneration. Acta Neuropathol 2014;128:397-410

118. van Langenhove T, van der Zee J, van Broeckhoven C. The molecular basis of the frontotemporal lobar degeneration-amyotrophic lateral sclerosis spectrum. Ann Med 2012;44:817-28.

119. Wider C, Dickson DW, Stoessl AJ, et al. Pallidonigral TDP-43 pathology in Perry syndrome. Parkinsonism Relat Disord 2009;15:281-6.

120. Kamada M, Izumi Y, Ayaki T, et al. Clinicopathologic features of autosomal recessive amyotrophic lateral sclerosis associated with optineurin mutation. Neuropathology 2014;34:64-70.

121. Koriath CAM, Bocchetta M, Brotherhood E, et al. The clinical, neuroanatomical, and neuropathologic phenotype of TBK1 -associated frontotemporal dementia: a longitudinal case report. Alzheimers Dement 2017;6:75-81.

122. Arai T. Significance and limitation of the pathological classification of TDP-43 proteinopathy. Neuropathology 2014;34:578-88.

123. Braak H, Ludolph A, Thal DR, et al. Amyotrophic lateral sclerosis: dash-like accumulation of phosphorylated TDP-43 in somatodendritic and axonal compartments of somatomotor neurons of the lower brainstem and spinal cord. Acta Neuropathol 2010;120:67-74.

124. Cairns NJ, Bigio EH, Mackenzie IRA, et al. Neuropathologic diagnostic and nosologic criteria for frontotemporal lobar degeneration: consensus of the Consortium for frontotemporal lobar degeneration. Acta Neuropathol 2007:114:5-22.

125. Cairns NJ, Neumann M, Bigio EH, et al. Tdp-43 in familial and sporadic frontotemporal lobar degeneration with ubiquitin inclusions. Am J Pathol 2007;171:227-40.

126. Irwin DJ, Cairns NJ, Grossman M, et al. Frontotemporal lobar degeneration: defining phenotypic diversity through personalized medicine. Acta Neuropathol 2015:129:469-91.

127. Lashley T, Rohrer JD, Mead S, et al. Review: an update on clinical, genetic and pathological aspects of frontotemporal lobar degenerations. Neuropathol Appl Neurobiol 2015;41:858-81.

128. Mackenzie IRA, Neumann M, Baborie A, et al. A harmonized classification system for FTLD-TDP pathology. Acta Neuropathol 2011;122:111-3.

129. Lee EB, Porta S, Michael Baer G, et al. Expansion of the classification of FTLD-TDP. distinct pathology associated with rapidly progressive frontotemporal degeneration. Acta Neuropathol 2017;134:65-78

130. Nelson PT, Schmitt FA, Lin Y, et al. Hippocampal sclerosis in advanced age: clinical and pathological features. Brain 2011;134:1506-18.

131. McKee AC, Stein TD, Kiernan PT, et al. The neuropathology of chronic traumatic encephalopathy. Brain Pathology 2015;25:350-64.

132. Dickson DW, Schneider JA, Rademakers R, et al. The TMEM106B locus and TDP-43 pathology in older persons without FTLDAuthor Response. Neurology 2015;85:1354.2-5.

133. McKee AC, Stern RA, Nowinski CJ, et al. The spectrum of disease in chronic traumatic encephalopathy. Brain 2013;136:43-64.

134. Sephton CF, Yu G. The function of RNA-binding proteins at the synapse: implications for neurodegeneration. Cell. Mol. Life Sci. 2015;72:3621-35.
135. Geser F, Martinez-Lage M, Kwong LK, et al. Amyotrophic lateral sclerosis, frontotemporal dementia and beyond: the TDP-43 diseases. J Neurol 2009;256:1205-14.

136. Nelson PT, Dickson DW, Trojanowski JQ, et al. Limbic-predominant agerelated TDP-43 encephalopathy (late): consensus Working Group report. Brain 2019;142:1503-27.

137. Munoz DG, Neumann M, Kusaka H, et al. Fus pathology in basophilic inclusion body disease. Acta Neuropathol 2009:118:617-27.

138. Neumann M, Rademakers R, Roeber $S$, et al. A new subtype of frontotemporal lobar degeneration with FUS pathology. Brain 2009;132:2922-31.

139. Neumann M, Roeber S, Kretzschmar HA, et al. Abundant FUS-immunoreactive pathology in neuronal intermediate filament inclusion disease. Acta Neuropathol 2009:118:605-16.

140. Davis RL, Holohan PD, Shrimpton AE, et al. Familial encephalopathy with neuroserpin inclusion bodies. Am J Pathol 1999;155:1901-13.

141. Davis RL, Shrimpton AE, Holohan PD, et al. Familial dementia caused by polymerization of mutant neuroserpin. Nature 1999:401:376-9.

142. Gourfinkel-An I, Duyckaerts C, Camuzat A, et al. Clinical and neuropathologic study of a French family with a mutation in the neuroserpin gene. Neurology 2007:69:79-83

143. Hagen MC, Murrell JR, Delisle M-B, et al. Encephalopathy with neuroserpin inclusion bodies presenting as progressive myoclonus epilepsy and associated with a novel mutation in the proteinase inhibitor 12 gene. Brain Pathol 2011;277:no-82.

144. Takao M, Benson MD, Murrell JR, et al. Neuroserpin mutation S52R causes neuroserpin accumulation in neurons and is associated with progressive myoclonus epilepsy. J Neuropathol Exp Neurol 2000;59:1070-86.

145. Vidal R, Ghetti B, Takao M, et al. Intracellular Ferritin Accumulation in Neural and Extraneural Tissue Characterizes a Neurodegenerative Disease Associated with a Mutation in the Ferritin Light Polypeptide Gene. J Neuropathol Exp Neurol 2004;63:363-80

146. Revesz T, Holton JL, Lashley T, et al. Genetics and molecular pathogenesis of sporadic and hereditary cerebral amyloid angiopathies. Acta Neuropathol 2009;118:115-30.

147. Robinson JL, Lee EB, Xie SX, et al. Neurodegenerative disease concomitant proteinopathies are prevalent, age-related and APOE4-associated. Brain 2018:141:2181-93

148. Williams DR, Holton JL, Strand C, et al. Pathological tau burden and distribution distinguishes progressive supranuclear palsy-parkinsonism from Richardson's syndrome. Brain 2007;130:1566-76.

149. Irwin DJ, Brettschneider J, McMillan CT, et al. Deep clinical and neuropathological phenotyping of Pick's disease. Ann Neurol 2015

150. Saito Y, Ruberu NN, Sawabe M, et al. Staging of argyrophilic grains: an ageassociated tauopathy. J Neuropathol Exp Neurol 2004;63:911-8.

151. Brettschneider J, Del Tredici K, Irwin DJ, et al. Sequential distribution of pTDP-43 pathology in behavioral variant frontotemporal dementia (bvFTD). Acta Neuropathol 2014;127:423-39.

152. Brettschneider J, Del Tredici K, Toledo JB, et al. Stages of pTDP-43 pathology in amyotrophic lateral sclerosis. Ann Neurol 2013;74:20-38.

153. Josephs KA, Murray ME, Whitwell JL, et al. Staging TDP-43 pathology in Alzheimer's disease. Acta Neuropathol 2014;127:441-50.

154. Josephs KA, Murray ME, Whitwell JL, et al. Updated TDP-43 in Alzheimer's disease staging scheme. Acta Neuropathol 2016;131:571-85.

155. Brettschneider J, Irwin DJ, Boluda S, et al. Progression of alpha-synuclein pathology in multiple system atrophy of the cerebellar type. Neuropathol App/ Neurobiol 2017:43:315-29

156. Brettschneider J, Suh E, Robinson JL, et al. Converging patterns of $\alpha$-synuclein pathology in multiple system atrophy. J Neuropathol Exp Neurol 2018;77:1005-16.

157. Liesinger AM, Graff-Radford NR, Duara R, et al. Sex and age interact to determine clinicopathologic differences in Alzheimer's disease. Acta Neuropathol 2018;136:873-85.

158. Oveisgharan $S$, Arvanitakis Z, Yu L, et al. Sex differences in Alzheimer's disease and common neuropathologies of aging. Acta Neuropathol 2018;136:887-900.

159. Gelpi E, Kovacs GG. Prion diseases: a primer for general pathologists. Diagnostic Histopathology 2011;17:217-24.

160. Ferrer I, Armstrong J, Capellari S, et al. Effects of formalin fixation, paraffin embedding, and time of storage on DNA preservation in brain tissue: a BrainNet Europe study. Brain Pathology 2007;17:297-303.

161. Lee EB. Integrated neurodegenerative disease autopsy diagnosis. Acta Neuropathol 2018;135:643-6.

162. Braak H, Del Tredici K. Alzheimer's pathogenesis: is there neuron-to-neuron propagation? Acta Neuropathol 2011;121:589-95. 